\title{
Sustainable Energy Skills in the Construction Sector ${ }^{\dagger}$
}

\author{
Agnieszka Kowalska ${ }^{1}$, Mohaddeseh Maktabifard ${ }^{2, *}$, Sylvain Kubicki ${ }^{3}$, Dragomir Tzanev ${ }^{4}$, \\ Peter Gyuris ${ }^{5}$, Seamus Hoyne ${ }^{6}$ and Jan Cromwijk ${ }^{7}$ \\ 1 ASM-Market Research and Analysis Centre, 99-301 Kunto, Poland; a.kowalska@asm-poland.com.pl \\ 2 R2M Solution, 06330 Roquefort-les-Pins, France \\ 3 Luxembourg Institute of Science and Technology (LIST), L-4362 Esch-sur-Alzette, Luxembourg; \\ sylvain.kubicki@list.lu \\ 4 Center for Energy Efficiency EnEffect, 1164 Sofia, Bulgaria; dtzanev@eneffect.bg \\ 5 Geonardo Environmental Technologies, 1031 Budapest, Hungary; peter.gyuris@geonardo.com \\ 6 Limerick Institute of Technology, E41 PC92 Tipperary, Ireland; seamus.hoyne@lit.ie \\ 7 ISSO, Dutch Building Services Knowledge Centre, Weena 505, 3013 AL Rotterdam, The Netherlands; \\ j.cromwijk@isso.nl \\ * Correspondence: mohaddeseh.maktabifard@r2msolution.com; Tel.: +33-773-165-480 \\ + Presented at the Sustainable Places 2020, Online, 28-30 October 2020; \\ Available online: https://www.sustainableplaces.eu/.
}

Published: 12 January 2021

\begin{abstract}
In this workshop we discussed the progress and results of six Horizon 2020 projectsINSTRUCT, BIMEET, The nZEB Roadshow, TRAIN4SUSTAIN, HP4All, and BUSLeague-about how to increase the number of skilled building professionals and/or blue-collar workers across the building design, operation, and maintenance value chain (designers, architects, engineers, building managers, technicians, installers, blue-collar workers including apprentices, and other building professionals), with a specific focus on the engagement of small and medium-sized enterprises (SMEs).
\end{abstract}

Keywords: skill; energy; construction; building professionals; small and medium-sized enterprises

\section{Introduction}

The European construction sector faces unprecedented challenges to achieve ambitious energyefficiency objectives that can be met only if successful training initiatives and supporting policy instruments are put in place, acting as a springboard to stimulate the demand for energy-efficiency skills.

The objective of this workshop was to discuss how to increase the number of skilled building professionals and/or blue-collar workers across the building design, operation, and maintenance value chain (designers, architects, engineers, building managers, technicians, installers, blue-collar workers including apprentices, and other building professionals), with a specific focus on the engagement of small and medium-sized enterprises (SMEs). Recourse to skilled professionals/workers both for renovations and new construction of buildings and district scale solutions should be made more attractive and easier for companies and homeowners alike.

Hence, in this report, we are summarizing the contributions of six Horizon 2020 projects on sustainable energy skills and training in the construction value chain, including: INSTRUCT [1], BIMEET [2], The nZEB Roadshow [3], TRAIN4SUSTAIN [4], HP4All [5] and BUSLeague [6]. In addition, recording of the workshop is available online as a Supplementary Material. 


\section{INSTRUCT}

The INSTRUCT project aims to act at a market level by providing an operational framework and set of services serving to increase the number of skilled building professionals and construction workers along the value chain, raising awareness of stakeholders in the construction value chainincluding producers and retailers, home and building owners, and tenants about environmental challenges and the benefits of sustainable energy skills - and paving the way for legislative changes that overall will stimulate the demand for energy skills. Project key outputs include:

- Quantitative and qualitative evidence that reinforces the link between energy skills and energy performance.

- A set of tools and instruments facilitating the mutual recognition of energy skills and qualifications in the construction sector (including e.g., sustainable-energy skill passports/registers, and new partnerships and initiatives).

- Real-world demonstrations (in five geographical European areas) of the usefulness and ease of use of the deployed instruments.

- New legislative frameworks and legislative-change proposals, thanks to which energy skills will need to be confirmed by certificates.

- Dissemination and awareness raising actions in consortium members' countries, scaled up to the wider Europe.

The 30-month project started in June 2020 and is being implemented by the Consortium of 8 Partners, which draws on the engagement of internationally leading industry best practice, research and vocational training, the educational excellence of leading institutions in Europe, and the robust experience of accrediting bodies in the construction domain. It provides Europe-wide coverage with seven participating countries, scaled up to five regional clusters, representing a multi-expertise ensemble of stakeholders and energy value chains deploying the INSTRUCT methodology and supporting tools in country-based pilots. It is supported by a network of stakeholders, involving the Build Up Skills chapters across Europe, already finished (BIMEET) and ongoing EU research projects and a Europe-wide community of interest of 200+ members.

\section{BIMEET}

The European construction sector is facing unprecedented challenges to achieve ambitious energy-efficiency objectives (with the aim to generalize near-zero energy buildings), in an economic crisis context dominated by reduced investments and a search for cost effectiveness and high productivity. Moreover, the industry is experiencing its digital revolution, with the Building Information Modeling (BIM) approach gaining significant interest across Europe. Member states implement very different approaches through regulations and maturity targets, which always face the traditional low-tech and informal practices of construction businesses (a fragmented sector, dominated by SMEs).

The BIMEET project aimed to leverage the take-up of ICT and BIM through a significant upgrade of the skills and capacities of the EU construction workforce. This Coordination and Support Action project was built around a strong consortium relying on educational and research expertise, the robust experience of accrediting and labeling bodies, the training supply chain, and a wide engagement of industry-led best practices (already committed in an EU-wide expert panel).

Through its actions the project (a) paved the way to a fundamental step change in delivering systematic, measurable, and effective energy-efficient buildings through BIM training with a view to effectively address European energy and carbon reduction targets; (b) promoted a well-trained world leading generation of decision makers, practitioners, and blue collars in BIM for energy efficiency; (c) established a world-leading platform for BIM for energy-efficiency training nurtured by an established community of interest. Its principal outputs were (1) a skills matrix related to BIM and energy efficiency, harmonized thanks to The European Qualifications Framework (EQF) standard, and (2) a training platform contributing to widely disseminating the BIMEET EQF. These results associated with a labeling scheme guaranteed the sustainability of the project results after its lifetime. 


\section{The nZEB Roadshow}

The nZEB Roadshow project will organize national-scale marketing and communication campaigns in five European countries, focused around nZEB days organized in three to five selected cities in each of Bulgaria, Croatia, Greece, Italy, and Romania. The nZEB weeks will consist of a multitude of events: Construction products and real estate fairs, practical demonstrations and realtime nZEB construction, training courses for designers and construction workers (with inclusion of BIM-enabled VR and AR solutions), information sessions and free consultations for citizens active in the real estate market, on-site training at public building renovation sites, and career orientation centers and construction job fairs with a focus on the local construction sector SMEs.

As a focal point of the events, the BKHs will get on wheels - through the design and construction of prefabricated modular mobile buildings that will serve as information and demonstration centers for raising awareness of the benefits and specificities of nZEB - and will create the necessary prerequisites for effective communication between stakeholders. With very careful attention to exterior and interior design, the centers will offer real-life experience of quality nZEB and will be equipped with all necessary technologies to provide full information on the processes with relevance to the building's performance in terms of comfort, internal air-quality parameters, and energy consumption.

In addition, the nZEB Roadshow will add to the current efforts to promote nZEB - related to two very important but unfortunately still largely missing components: professional marketing and sales services, and strong media partnerships.

\section{TRAIN4SUSTAIN}

The TRAIN4SUSTAIN (T4S) project was constituted for stimulating the demand for skilled construction-sector professionals (architects, contractors, SMEs, and workers) through raising acceptance of regional and national qualifications and skills on the EU construction market. We believe that comparability of national qualifications and sustainable-energy skills is key for increased transparency and penetration power in the market. T4S is tackling the issue of mutual recognition of qualifications and skills so that training accredited in one country could be recognized easier in another country.

The project is set to analyze already available transnational energy-skill qualification frameworks for building professions, such as the Prof/Trac project's scheme or the ones produced by the BIM community. A very important methodological approach that will be used throughout the project implementation and create the qualification standard is the recently developed EU framework for the assessment of energy and resource efficient buildings, also known as the Level(s) initiative. The T4S project focuses on acting at market level, collaborating with relevant training providers, and building assessment providers and scheme operators.

The project consortium will build on its activities with continuous consultation with stakeholders as well as ultimate end-users. The T4S project aims at fostering a common understanding of sustainable-energy skills across Europe by promoting a competence quality standard, a European Skills Registry, and a Skills Passport for facilitating transnational recognition of learning outcomes and skill levels of existing qualifications and vocational training.

\section{HP4All}

HP4All brings together leading experts across Europe to enable capacity and skills development within the heat-pump sector and to ensure that the energy-efficiency gains afforded by heat pumps are realized. HP4All, following a holistic, systemic point of view, will work both with the supply side (manufacturers, SMEs, installers, etc.) and demand side (building owners, public sector, etc.). This way, the project will enhance, develop and promote the skills required for high-quality, optimized heat pump (HP) installations within residential/nonresidential buildings, bringing Europe to the forefront of the climatization sector. 
Over $1.1 \mathrm{~m}$ heat pumps were installed in 2017 across Europe, with the sector seeing a 100\% growth since 2006. As the transition to electrification of heat speeds up, this growth rate is set to increase further. HP4All will develop the HP4All package, a set of innovative tools and resources to be used by the different related stakeholders. The package includes:

- An HP competency framework to facilitate mutual recognition of HP skills across Europe and the construction sector.

- From an end-user perspective, a digital HP knowledge hub will be created to provide guidance, support and tools, e.g., technical information, case studies, and procurement guidance to increase the demand for HP skills and knowledge.

- An HP benchmarking tool will enable end users to consider options and performance of HP technologies within different building types.

The HP4All package will be validated through three regional plans being implemented (AT, ES, and IE) with the ambition of driving market change, influencing end-user decisions, and planning for new innovations. The implementation plans will be informed by extensive stakeholder engagement to map current and future barriers to HP market exploitation and skills development:

- 400 people will receive capacity-building and guidance interventions at the regional/national level to build skills/knowledge on new innovations and HP solutions, e.g., smart-grid integration, hybrid technologies, etc. Large promotional campaigns for end users will be held.

- $>20$ case studies/best practices showcasing the impact of skills on HP performance will be created.

- $\quad>10$ workshops with policy makers, manufacturers and supply chains will be held.

- Campaigns will be held in 10 DIY stores and recommendations regarding policy and procurement development will be made.

Moreover, critical to the success of HP4All is the focus on new innovations and emerging solutions in the HP market, and the skills associated with their application. To that end, 20 leading experts in the HP and energy sectors will support the regional actors to prepare the market for new innovations related to HP technology, procurement, and contracting services.

The impact of the project will be maximized through the role of the observers (HR, PT, RO) as they will follow closely the development and validation of the HP4All package, becoming early adopters even before the project ends. Moreover, a replication plan will be developed, including train-the-trainer actions, a roadmap for HP4All package use, and an outreach awareness campaign that includes the organization of a pan-European event targeting public bodies. Thus, HP4All will ultimately address HP Skills in all countries, for all HP building types and also all HP types and innovations.

\section{BUSLeague}

The overall aim of BUSLeague is to address and overcome the challenges of the stimulation of demand for an energy skilled workforce (demand side), along with hands-on capacity building to increase the number of skilled workforces across the building design, operation, and maintenance value chain (supply side). BUSLeague will achieve this objective by developing and implementing a cross-European recognition of energy skills, together with upscaling successful training methods and techniques that have already been developed in previous EU and national initiatives such as Build Up Skills and Construction Skills. BUSLeague focuses on a blend of four elements: mutual recognition of energy skills, awareness raising, capacity building, and legislative changes.

Implementation will be done at country-specific and regional levels, based on a blend of measures to stimulate demand complemented with hands-on and practical up-skilling of involved local and regional workforces. In this way, engagement of SMEs will be ensured. BUSLeague is formed by a coalition of former Build Up Skills and Construction Skills projects. The partners believe that by working together the national implementation plans and developed means will improve and become more attractive and effective. BUSLeague is strengthened by experienced anthropology 
researchers and educational technology researchers in order to prove impact and to optimize the blends for stimulating demand and optimizing learning transfer of applied learning means and materials.

\section{Conclusions}

The importance of identifying the potential synergies among the above projects in order to reinforce and boost the skills and energy efficiency in the construction sector was addressed. This identification supports the projects in achieving the objectives planned by the European Union within the established policy framework and directives in place. Among all revised EPBD 2018/844/EU and article 2a: long-term renovation strategies to encompass an overview of national initiatives to promote skills and education in the construction and EE sectors, precisely highlighted the importance of trainings and skillful professionals in the building sector.

These energy-efficiency and renewable-energy directives emphasize the significance of measures to support the increase of renewable heating and cooling, and qualified installers in the building sector. In addition, launch of the renovation strategy published by the European Commission during October 2020 strengthened the importance of these measures ("Renovation Wave: doubling the renovation rate to cut emissions, boost recovery and reduce energy poverty", 2020) [7].

According to the Renovation Wave, doubling the renovation rate to cut emissions, boost recovery, and reduce energy poverty has six general leading actions:

1. Set stronger regulations, standards, and information regarding energy performance to improve incentives for public and private owners to undertake renovations.

2. Ensure adequate, accessible, and well-targeted financing to aid the process of combining different funding, and multiple incentives for private funding.

3. Increase the capacity of developers to develop renovation projects, and training and skills development for workers.

4. Expand the market for sustainable building products and services, including the incorporation of sustainable materials, and revised legislation.

5. Create a New European Bauhaus, with support of an advisory board consisting of external experts including scientists, architects, designers, planners, artists, and civil society.

6. Develop neighborhood-based approaches for local communities to corporate renewable solutions towards the path of zero-energy districts.

Moreover, this new Renovation Wave strategy underlines that the transformation towards climate-neutral construction will only be achievable if existing jobs include circular skills and if new green jobs also emerge in this context-job profiles such as professionals in deep building renovation, installers for advanced renewable technological solutions or building information modeling specialists. Furthermore, boosting know-how, workers' skills in the renovation sector, and the support provided by the Build Up skills initiative is underlined by this Renovation Wave.

In summary, identifying the potential synergies among the above projects is based on:

- $\quad$ Projects building on the results of previous projects from the Build Up skills program and also from other EU and national programs.

- $\quad$ Producing practical and innovative tools addressing specific gaps within a project.

- Collaborating with industries and directly involving them to develop tools evolved within the projects.

- Boosting the supply and the demand for skilled workers, both white and blue collars.

- Renewed focus on supporting public authorities followed by expected changes in legislation and enabling public procurement procedures.

Supplementary Materials: The recording of the workshop is available online at https://www.sustainableplaces.eu/home/sp20-workshops-events/sp20-sustainable-energy-skills-in-theconstruction-sector/. 
Author Contributions: Introduction, A.K., M.M.; presentation of BIMEET, S.K.; presentation of The nZEB Roadshow, D.T.; presentation of TRAIN4SUSTAIN, P.G.; presentation of HP4All, S.H.; presentation of BUSLeague, J.C. All authors have read and agreed to the published version of the manuscript.

Funding: These projects have received separate funding from the European Union's Horizon 2020 research and innovation program under the following grant agreements: INSTRUCT: No. 894756; BIMEET: No. 753994; The nZEB Roadshow: No. 892378; TRAIN4SUSTAIN: No. 894514; HP4All: No. 891775 and BUSLeague: No. 892894.

Conflicts of Interest: The authors declare no conflict of interest.

\section{References}

1. INSTRUCT's. Available online: http://www.instructproject.eu (accessed on 18 October 2020).

2. BIMEET's Page on Community Research and Development Information Dervice (CORDIS). Available online: http://cordis.europa.eu/project/id/753994 (accessed on 18 October 2020).

3. The nZEB Roadshow's. Available online: http://www.nzebroadshow.eu/\# (accessed on 18 October 2020).

4. TRAIN4SUSTAIN's. Available online: http://train4sustain.eu (accessed on 18 October 2020).

5. HP4All's. Available online: http://hp4all.eu (accessed on 18 October 2020).

6. BUSLeague's Page on Community Research and Development Information Service (CORDIS). Available online: http://cordis.europa.eu/project/id/892894 (accessed on 18 October 2020).

7. Renovation Wave: Doubling the Renovation Rate to Cut Emissions, Boost Recovery and Reduce Energy Poverty 14 October 2020 Press Release Page on the European Commission. Available online: https:/ec.europa.eu/commission/presscorner/detail/en/IP_20_1835 (accessed on 19 October 2020).

Publisher's Note: MDPI stays neutral with regard to jurisdictional claims in published maps and institutional affiliations.

(C) 2021 by the authors. Licensee MDPI, Basel, Switzerland. This article is an open access article distributed under the terms and conditions of the Creative Commons Attribution (CC BY) license (http://creativecommons.org/licenses/by/4.0/). 